\title{
Hematidrosis: A Fascinating Phenomenon- Case Study and Overview of the Literature
}

\author{
Maamoun Alsermani, MD ${ }^{1}$ Hazzaa Alzahrani, MD ${ }^{1}$ \\ 1 Department of Adult Hematology, Bone Marrow Transplantation, \\ Oncology Center, King Faisal Specialist Hospital and Research \\ Center, Riyadh, Saudi Arabia \\ Semin Thromb Hemost 2018;44:293-295.
}

\author{
Riad El Fakih, MD ${ }^{1}$
}

\begin{abstract}
Address for correspondence Riad El Fakih, MD, Department of Adult Hematology, Bone Marrow Transplantation, Oncology Center, MBC 64, King Faisal Specialist Hospital and Research Center, POB 3354, Riyadh 11211, Saudi Arabia

(e-mail: relfakih1@kfshrc.edu.sa; riadfakih@hotmail.com).
\end{abstract}

As previously explored in this journal, the investigation of bleeding symptoms involves a systematic investigative approach that includes investigation of patient and family history, physical examination, and laboratory testing. ${ }^{1}$ Although this is also true of an investigation into pediatric bleeding, there are special considerations required, including the reduced period of capture for personal history, and fewer hemostatic challenges. ${ }^{2}$ Sometimes, such investigations prove fruitless and do not uncover a true bleeding diathesis. Hematidrosis is one such example.

Hematidrosis is a fascinating disorder characterized by blood oozing from the intact skin and mucous membranes in the absence of a bleeding problem. It frequently affects young girls (i.e., typically between 9 and 13 years) under stressful situations, and probably suffering from an underlying anxiety disorder. These patients usually undergo a thorough and expensive hematology evaluation aimed to identify a possible underlying bleeding disorder, but which fails to provide the answer. Here, we report a case of a 9-year-old girl exposed to bullying at school, which leads to recurrent bleeding episodes.

The young patient had no prior medical or psychological illness and presented to our clinic following a 5-month history of recurrent spontaneous blood loss from skin, scalp, ear, mouth, and eyes (-Fig. 1). Her parents claimed that the episodes happen twice weekly on average, mostly in the evening, and with no clear precipitating factors. Each episode lasted for 1 or 2 minutes and was usually self-limited. Family history was negative for any bleeding disorders. She was evaluated by her family physician and a local hematologist, and a workup for common bleeding disorders was unrevealing (-Table 1). The patient also underwent upper gastrointestinal endoscopy because some of these episodes were accompanied by bleeding from her mouth. The endoscopy and biopsy were consistent with celiac disease, which was later confirmed by serological testing. Nevertheless, no clinical signs of celiac disease could be recorded. Upon her evaluation in our clinic, her vital signs and growth chart were within normal limits, and physical examination was unrevealing; specifically, there were no signs of self or secondary-inflicted injuries (scars, fresh cuts, scratches, or wounds). On further questioning, the parents reported that these episodes did not occur on holidays and usually happened on the days she attended school. The patient admitted that she always felt intimidated and emotionally abused by her school colleagues. A sampling of the fluid discharge confirmed the presence of red and white blood cells along with epithelial cells.

Hematohidrosis or hematidrosis is a rare and largely mysterious phenomenon, with only a few case reports having been published. ${ }^{3-14}$ Reported patients are usually young girls, ${ }^{3,5}$ and present with blood oozing from intact skin or mucous membranes in the setting of stress and anxiety. ${ }^{11}$ The episodes last for few minutes, ${ }^{3}$ and resolve almost spontaneously. ${ }^{5}$ The workup for bleeding disorders is usually normal, and the examination of the bloody fluid demonstrates the presence of blood elements. It is important to carefully examine the skin to rule out self-inflicted or secondary injuries (e.g., potentially pointing to Munchausen's syndrome or Munchausen's by proxy) and to also differentiate this entity from chromhidrosis (color pigment in sweat), vasculitis, scurvy, or other connective tissue disorders (where vascular fragility can lead to easy bleeding). Some of the reported cases underwent biopsy of the oozing areas with active bleeding and did not show any histopathological findings. ${ }^{4,5}$ Although the frightening presentation of hematidrosis leads to immediate medical evaluation in most of the cases, the diagnosis is often delayed because the condition is a rare and frequently overlooked phenomenon. Frequently, patients will have extensive evaluations including hematology consultation before reaching a correct diagnosis. The etiology remains mostly unknown. Stress-induced vasoconstriction (through adrenergic stimulation) in the small blood vessels around the sweat glands and eventually leading to vascular rupture and blood extravasation with the sweat is the proposed cause. ${ }^{10,11}$ The fact that most cases
Issue Theme Editorial Compilation V; Guest Editors: Emmanuel J. Favaloro, PhD, FFSc (RCPA), and Giuseppe Lippi, MD.
Copyright (c) 2018 by Thieme Medical Publishers, Inc., 333 Seventh Avenue, New York, NY 10001, USA. Tel: +1(212) 584-4662.
DOI https://doi.org/ 10.1055/s-0037-1608905. ISSN 0094-6176. 


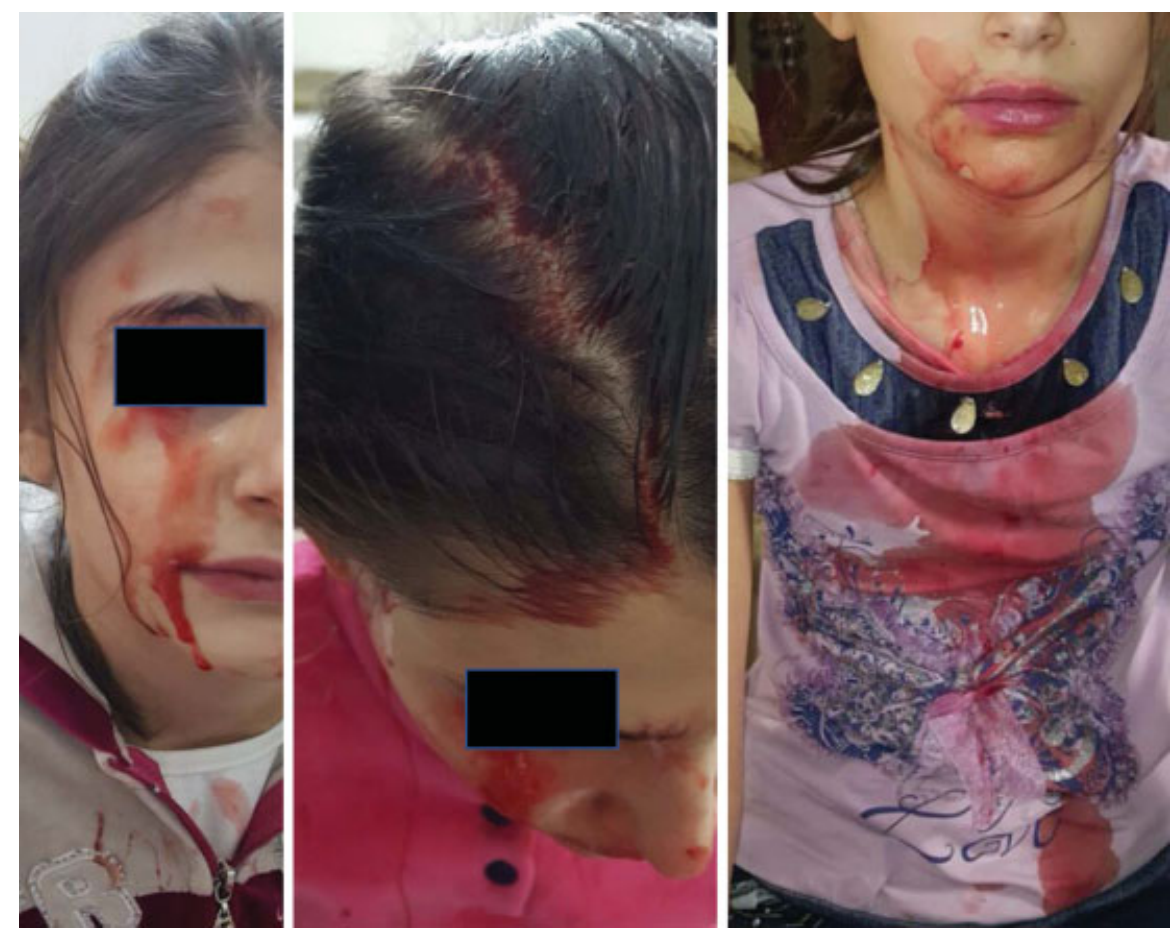

Fig. 1 Spontaneous blood loss from skin, scalp, ear, mouth, and eyes during one of the bleeding episodes.

Table 1 Summary of the relevant investigations performed as a part of the initial bleeding workup

\begin{tabular}{|l|l|}
\hline Test/analyte & Patient result (normal range) \\
\hline Platelets & $241 \times 10^{9} / \mathrm{L}\left(150-400 \times 10^{9} / \mathrm{L}\right)$ \\
\hline Prothrombin time & $12.9 \mathrm{~s}(12.3-14.2 \mathrm{~s})$ \\
\hline Activated partial thromboplastin time & $31.4 \mathrm{~s}(30.5-40.4 \mathrm{~s})$ \\
\hline Factor VIII activity & $85 \%(60-150 \%)$ \\
\hline Factor IX activity & $90 \%(60-150 \%)$ \\
\hline von Willebrand factor: Ristocetin cofactor activity & $100 \mathrm{IU} / \mathrm{dL}(50-200 \mathrm{IU} / \mathrm{dL})$ \\
\hline von Willebrand factor: Antigen & $70 \mathrm{IU} / \mathrm{dL}(50-150 \mathrm{IU} / \mathrm{dL})$ \\
\hline $\begin{array}{l}\text { Platelet aggregation (adenosine diphosphate, collagen, arachidonic acid, } \\
\text { thrombin, epinephrine, ristocetin) recorded by light transmission }\end{array}$ & Normal \\
\hline PFA-100 (C/Epi cartridge) & $112 \mathrm{~s}(78-199 \mathrm{~s})$ \\
\hline
\end{tabular}

Abbreviations: C/Epi, collagen/epinephrine; PFA-100, platelet function analyser-100.

respond to $\beta$ adrenoreceptor blockers and/or anxiolytics makes this theory plausible., ${ }^{40}$ Our patient was treated with propranolol $10 \mathrm{mg}$ twice daily and her symptoms resolved. As in all the reported cases, an underlying cause usually precipitates the episodes of anxiety that lead to bleeding. The trigger in our case was identified as bullying at school; the patient and her parents were referred to psychiatry and social services for further help. The association of hematidrosis with celiac disease in our case might or might not be significant.

To conclude, hematidrosis is an interesting bleeding phenomenon where a psychological trigger (rivalry, scolding, punishment, bullying, etc.) leads to a sequence of events culminating in bleeding from intact skin and mucous membranes. This can be a frightening experience for the patient and family and often leads to extensive unnecessary testing and sometimes even to dangerous therapeutic intervention (e.g., a case was treated with fresh frozen plasma several times ${ }^{4}$ ). Reporting such enigmatic cases might help educate the public as well as the medical society about a relatively simple yet frightening phenomenon that can exhaust resources and even lead to unnecessary therapeutic or diagnostic interventions. In the end, we decided not to pursue additional invasive investigations above those already undertaken ( - Table 1 ) based on our evaluation of this case, successful treatment with propranolol, and our conclusion that the case was indeed that of the rare condition hematidrosis.

\section{Conflict of Interest}

None. 


\section{References}

1 Rydz N, James PD. Approach to the diagnosis and management of common bleeding disorders. Semin Thromb Hemost 2012;38 (07):711-719

2 Revel-Vilk S. Clinical and laboratory assessment of the bleeding pediatric patient. Semin Thromb Hemost 2011;37(07):756762

3 Jayaraman AR, Kannan P, Jayanthini V. An interesting case report of hematohidrosis. Indian J Psychol Med 2017;39(01):83-85

4 Wang Z, Yu Z, Su J, et al. A case of hematidrosis successfully treated with propranolol. Am J Clin Dermatol 2010;11(06):440-443

5 Bhattacharya S, Das MK, Sarkar S, De A. Hematidrosis. Indian Pediatr 2013;50(07):703-704

6 Jafar A, Ahmad A. Child who presented with facial hematohidrosis compared with published cases. Case Rep Dermatol Med 2016; 2016:5095781

7 Tshifularo M. Blood otorrhea: blood stained sweaty ear discharges: hematohidrosis; four case series (2001-2013). Am J Otolaryngol 2014;35(02):271-273
8 Praveen BK, Vincent J. Hematidrosis and hemolacria: a case report. Indian J Pediatr 2012;79(01):109-111

9 Carvalho AC, Machado-Pinto J, Nogueira GC, Almeida LM, Nunes MB. Hematidrosis: a case report and review of the literature. Int J Dermatol 2008;47(10):1058-1059

10 Manonukul J, Wisuthsarewong W, Chantorn R, Vongirad A, Omeapinyan P. Hematidrosis: a pathologic process or stigmata. A case report with comprehensive histopathologic and immunoperoxidase studies. Am J Dermatopathol 2008;30(02):135-139

11 Jerajani HR, Jaju B, Phiske MM, Lade N. Hematohidrosis: a rare clinical phenomenon. Indian J Dermatol 2009;54(03):290-292

12 Zhang FK, Zheng YL, Liu JH, et al. Clinical and laboratory study of a case of hematidrosis [in Chinese]. Zhonghua Xue Ye Xue Za Zhi 2004;25(03):147-150

13 Patel RM, Mahajan S. Hematohidrosis: A rare clinical entity. Indian Dermatol Online J 2010;1(01):30-32

14 Bhagwat PV, Tophakhane RS, Rathod RM, Shashikumar BM, Naidu V. Hematohidrosis. Indian J Dermatol Venereol Leprol 2009;75 (03):317-318 